\section{In the business of synthesis}

\author{
Robert M. Joyce
}

Petrochemicals: The Rise of an Industry. By Peter H. Spitz. Wiley: 1988. Pp. 588. $\$ 29.95, £ 25.95$.

OF THE many changes in the American way of life triggered by the Japanese attack on Pearl Harbor in 1941, little publicity has been given to one of the outstanding technological achievements of the modern era. Within two years, engineers had designed, constructed and put into operation plants that increased US production of 100 -octane aviation gasoline and the new synthetic rubbers, GRS, Buna S and neoprene, by factors ranging from 15 to 180 over prewar levels. Concurrently, plants had to be built to produce the intermediates on which these materials were based: lower olefins for alkylate, and styrene, butadiene, isobutylene and acetylene for the rubbers.

Petrochemicals is primarily the story of the dramatic expansion of the US chemical industry after 1941. As Spitz makes clear, the experience and shared information gained by the companies involved in the wartime feat were key factors in the subsequent explosive growth of the industry.

The book begins with historical accounts of the origin, primarily in Germany, of the synthetic chemical industry based on coal tar intermediates, and of its prewar status in the United States. The latter history is framed in vignettes of four companies which were prime movers of the US industry into petroleum raw materials: Union Carbide, Shell Chemical, Dow and Standard Oil of New Jersey. Some of the history is inaccurate, and is flawed by technical errors. On tetraethyl lead, Spitz states (p. 91): "General Motors and Standard Oil (N.J.) subsequently founded the Ethyl Corporation and a new industry was born". Actually, General Motors first came to Du Pont, who developed a process for TEL and commercialized it in 1923; Ethyl Corporation was essentially only a legal entity until construction of their first plant in 1936. And (to give just one example) Cellosolve (ethoxyethanol) is identified as an ether based on ethylene oxide and cellulose (p.79).

The next two chapters describe the developments of the late 1930 s and early 1940s - catalytic cracking, platforming and separations technology - that put petroleum feedstock on a firm footing as a source of chemical intermediates. These accounts are salted with interesting biographical portraits of seminal contributors to the fields, and illustrated with many complex unit-process diagrams. As a necessary prelude to discussing the postwar industry, Spitz intercalates an interesting chapter on the cartels that characterized much of the industry in the late nineteenth and early twentieth centuries. By the 1930s, however, cartels had come into disfavour in the United States, and by the end of the Second World War the stage was set for all comers to seek the perceived gold to be found in the new synthetic chemicals and polymers.

Spitz provides some historical background and descriptions of the underlying technical advances. Here again there are errors. Thus (p. 279): "Paul Schlack - of IG - started work on polycondensation in 1928, several years before Carothers"; actually, Carothers came to Du Pont in

competition, not only from other US firms but also from aggressive companies in Europe and Japan and, later, from oilproducing countries in the Middle East. Spitz's description of the rise and shakeout of the vinyl chloride industry is an object lesson for planners and managers.

The best chapter in the book is the last, in which the author describes how the industry seems finally to have assimilated the lessons of the $1950 \mathrm{~s}-1970 \mathrm{~s}$, in no small measure the hard way. Many older, uneconomical petrochemicals plants have been shut down, and a large number of petrochemicals manufacturers have abandoned or sold their commodity chemicals businesses. His analysis of the

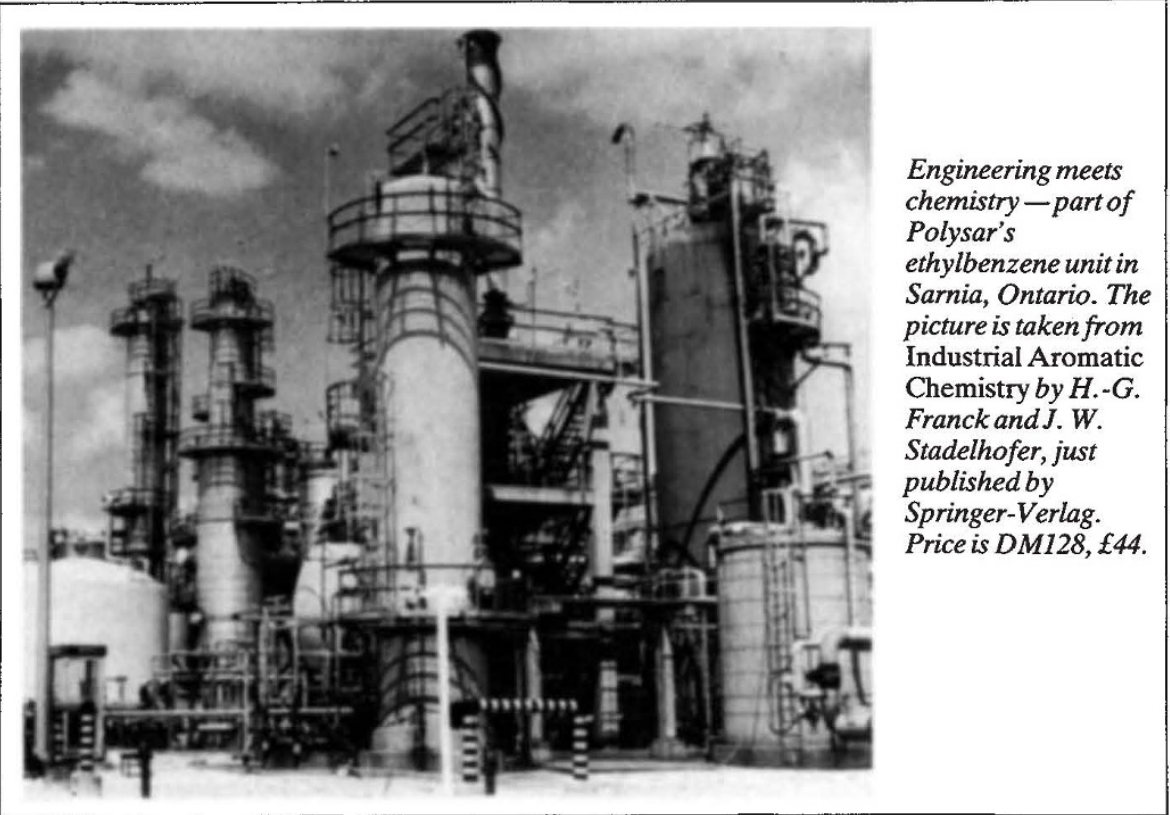

February 1928 and began work on polycondensation almost immediately.

Synthetic fibres and plastics are identified as the triggers for the postwar expansion of the chemical industry. The boom was fuelled in part by public perception that nylon, polyethylene and synthetic rubbers were not merely 'ersatz,' but were useful materials with unusual properties. In addition, intermediates based on petrochemicals were required to make them, and many companies, particularly those in the petroleum business, quickly came to view synthetic chemicals and polymers as opportunities to broaden their base. Much key technology could be gleaned from government reports on the postwar inspection of German plants. The only patent protection in the area was on proprietary catalysts and process details, and these patents could often be circumvented by hiring an engineer from a competitor or by drawing on the knowledge of a contract firm that had built a competitor's plant.

Many US firms who joined the 'gold rush' into petrochemicals found it at best marginally profitable because of heavy problems - some self-inflicted - in the growth of the industry and of their underlying causes is instructive reading for practising engineers and executives.

But this is not a satisfying book. It suffers from poor editing and proof-reading - many chemical names are improperly hyphenated or improperly separated into two more words, different names are used for the same compound and isomer indicators are not set in italics. The chemical index appears to have been created by a computer search of the text without any judgment being brought to bear on the result. Thus (and there are many more such examples) "metallic bromine" (!) from p. 327 of the text is listed under "M".

Altogether, the author would have done well to heed his own words (p. 132) about his teacher W. K. Lewis: "He taught his students to be clear and concise in their communications as engineers, particularly when addressing non-technical people".

Robert M. Joyce, 1518 Valley Forge Boulevard, Sun City Center, Florida 33570, USA, is editorial coordinator of the book series Organic Reactions and a former director of research for Du Pont. 